\title{
Comment
}

Neuro epidemiology

Neuroepidemiology 2013;41:86-87

DOI: $\underline{10.1159 / 000351497}$

\section{Still a Need for Data from Developing Countries on Traumatic Spinal Cord Injury}

\section{Ellen Merete Hagen}

Spinal Cord Injury Centre of Western Denmark, Department of Neurology, Viborg Regional Hospital, Viborg, Denmark

Traumatic spinal cord injury (TSCI) is a relatively rare but devastating condition. The epidemiology of TSCI has been studied extensively over the past 40 years. However, reliable information on the epidemiology for TSCI is still unavailable for much of the globe.

The first global report on spinal cord injury epidemiology was published in 2004 by Ackery et al. [1], followed by Wyndaele and Wyndaele [2] and van den Berg et al. [3] in 2010. Cripps et al. [4] published in 2011 a comprehensive review of the global epidemiology for TSCI and noted incidence rates ranging from 236 to 1,009 per million. Data on incidence were predominantly from developed regions [4].

Hagen et al. [5] found annual incidences ranging from 2.3 per million in a Canadian study to 83 per million in Alaska. The huge variation is due to differences in definition, inclusion, classification and procedures for identification of patients, as well as geographical and cultural differences [5]. Dryden et al. [6] found that the risk of TSCI is 2.5 times higher in rural than in urban areas. Traffic accidents (4-89\%) followed by falls (3-82\%) are the most common causes of TSCI in most countries [5].

Lee et al. [7] published earlier this year an update on the previous data made by Cripps et al. [4] including papers published before June 30, 2011. They identified 133 papers from 45 countries. A global-incident rate (2007) is estimated at 23 TSCI cases per million: North America (40 per million), Western Europe (16 per million) and Australia (15 per million); by extrapolation, Central Asia (25 per million), South Asia (21 per million), the Caribbean (19 per million), Latin America, the Andean region (19 per million), Central Latin America (24 per million), Southern Latin America (25 per million), Sub-Saharan Central Africa (29 per million), SubSaharan East Africa (21 per million) [7].

There are large variations in the gender distribution. Most studies show a preponderance of men [5]. In the recent update from Lee at al. [7], 46.7\% of all included papers reporting on gender have a male preponderance $\geq 80 \%$. In Africa (Nigeria, Sierra Leone and South Africa), Brazil and Vietnam, $\geq 90 \%$ of reported TSCI patients are men [7].

\section{KARGER}

E-Mail karger@karger.com

www.karger.com/ned
The proportion of TSCI resulting from motor vehicle crashes is stable or decreasing in developed countries, but on the increase in developing countries [7]. Low falls (1-metre or less) in elderly individuals, which often results in tetraplegia, are increasing in developed countries with ageing populations [5]. In developing countries, low falls resulting in TSCI occur while carrying heavy loads on the head in young people [7].

There is a tendency of more tetraplegics in developed countries [7]. The variations between the countries with regard to neurological level may partly be explained by different causal patterns. Also the availability of treatment, geographically and financially, may contribute to a general underreporting of TSCI. Due to socioeconomic conditions, patients with cervical injuries may have reduced chances of reaching a hospital alive in many developing countries [5].

In this issue of Neuroepidemiology, Rahimi-Movaghar et al. [8] describe the epidemiology of TSCI in the developing world. The incidence of TSCI in developing countries ranges from 2.1 to $130.7 / \mathrm{million} /$ year. Males comprised $82.8 \%$ of all TSCIs with a mean age of 32.4 years. The two leading causes of TSCI were found to be motor vehicle crashes $(41.4 \%)$ and falls (34.9\%). Complete TSCIs were found to be more common than incomplete injuries (56.5 vs. $43.0 \%$ ). Similarly, paraplegia was found to be more common than tetraplegia (58.7 vs. $40.6 \%$ ) [8].

The results of this study are of special interest. Although Lee et al. [7] have published an update, the number of papers from developing countries is still low, and there is a need for a special focus on TSCI in developing countries. Compared to major health issues, spinal cord injuries comprise a small number of patients who often need expensive treatment and rehabilitation. The International Spinal Cord Society (ISCoS) and WHO have joined forces in areas where they can make the greatest difference in spinal cord injuries, especially in prevention and educational issues worldwide [9]. Rahimi-Movaghar et al. [8] contribute with data necessary for this work. The leading causes for TSCI are motor vehicle crashes and falls, which are preventable injuries.

The study had several strengths: the authors did an extensive search using Embase, Medline and websites, and non-English papers were translated prior to review. Also two independent researchers performed data extraction separately and the results were compared.

The review demonstrates that there are still many developing countries where epidemiological data on TSCI are missing. The authors identified 64 papers from 28 developing countries through an extensive search. There is a wide range in incidence of TSCI from 2.1 to $130.7 /$ million/year. Bulgaria, Iran, Brazil, China and South Africa have the highest reported incidence ( $>50 /$ million/ year), and specific intervention targeting prevention in these countries is needed. 


\section{References}

$\checkmark 1$ Ackery A, Tator C, Krassioukov A: A global perspective on spinal cord injury epidemiology. J Neurotrauma 2004;21:1355-1370.

-2 Wyndaele M, Wyndaele JJ: Incidence, prevalence and epidemiology of spinal cord injury: what learns a worldwide literature survey? Spinal Cord 2006; 44:523-529.

- 3 Van den Berg ME, Castellote JM, Mahillo-Fernandez I, de Pedro-Cuesta $\mathrm{J}$ : Incidence of spinal cord injury worldwide: a systematic review. Neuroepidemiology 2010;34:184-192.

4 Cripps RA, Lee BB, Wing P, Weerts E, Mackay J, Brown D: A global map for traumatic spinal cord injury epidemiology: towards a living data repository for injury prevention. Spinal Cord 2011;49:493-501.

5 Hagen EM, Rekand T, Gilhus NE, Gronning M: Traumatic spinal cord injuries - incidence, mechanisms and course. Tidsskr Nor Laegeforen 2012;132:831-837.
6 Dryden DM, Saunders LD, Rowe BH, May LA, Yiannakoulias N, Svenson LW, et al: The epidemiology of traumatic spinal cord injury in $\mathrm{Al}-$ berta, Canada. Can J Neurol Sci 2003;30:113-121.

7 Lee BB, Cripps RA, Fitzharris M, Wing PC: The global map for traumatic spinal cord injury epidemiology: update 2011, global incidence rate. Spinal Cord 2013, E-pub ahead of print

$\checkmark 8$ Rahimi-Movaghar V, Sayyah MK, Akbari H, Khorramirouz R, Rasouli MR, Moradi-Lakeh M, et al: Epidemiology of traumatic spinal cord injury in developing countries: a systematic review. Neuroepidemiology 2013;41:65-85.

-9 Biering-Sørensen F, Bickenbach JE, el Masry WS, Officer A, von Groote PM: ISCoS-WHO collaboration. International Perspectives of Spinal Cord Injury (IPSCI) report. Spinal Cord 2011;49:679-683. 